\title{
Althusser e Pêcheux: um encontro paradoxal
}

Mónica G. Zoppi Fontana

\begin{abstract}
This article aims to reflect on the intellectual production of the philosophers Louis Althusser and Michel Pêcheux, considering an analysis of their texts written at the beginning of the years 1980 that circulated through different modalities: lectures, publications, interviews, editions in other languages. We are going to analyse these materials that, not with standing were produced during the years 1980, were published in French only during the years 1990 .
\end{abstract}

Key-words: Historical Materialism; French Discourse Analysis; Interpretation of Texts; Historical Event.

Resumo: Este artigo busca refletir em torno da produção intelectual dos filósofos Louis Althusser e Michel Pêcheux, com base em uma análise de seus textos escritos no início dos anos 1980, que circularam através de diferentes modalidades tais como: conferências, publicações, entrevistas, edições em outras línguas, tendo sido somente publicados em língua Francesa, entretanto, a partir dos anos 1990.

Palavras-chave: Materialismo Histórico; Análise de Discurso Francesa; Interpretação de textos; Acontecimento histórico.

AAnálise de discurso, tal como praticada por Michel Pêcheux e colaboradores a partir de meados dos anos sessenta até início dos anos noventa na França se inscreve explicitamente no materialismo histórico, a partir de uma leitura althusseriana de Marx. A referência a Althusser e aos autores clássicos do marxismo (Marx, Engels, Lenin, Mao Tse Tung, entre outros) é explícita nos textos teóricos assinados por Pêcheux individualmente ou em coautoria com seus colegas de pesquisa e militância. Pêcheux aponta, em um célebre artigo em coautoria publicado originalmente na revista Langages $24^{1}$, para as mudanças de terreno - da língua ao discurso, ou da teoria da língua à teoria do discurso - produzidas pela Análise de Discurso como efeito de sua inscrição no materialismo histórico ${ }^{2}$. Nesse artigo está expressa a aproximação da "teoria do discurso" à proposta central do materialismo histórico, a saber: a de produzir uma 'mudança de terreno' epistemológica (e política) que permita, nas palavras de Pêcheux:

[...] se desvencilhar da problemática subjetivista centrada no indivíduo [...] e compreender que o tipo de concreto com que lidamos e em relação ao qual é preciso pensar, é precisamente o que o materialismo histórico designa pela expressão relações sociais, que resulta de relações de classe características de uma formação social dada (através do modo de produção que a

1 Haroche, C.; Henry, P.; Pêcheux, M. (2007[1971]) “A Semântica e o corte saussuriano: língua, linguagem, discurso".

2 Remetemos ao artigo em coautoria Amaral, MV. B. e Zoppi Fontana, M.G.(2014) que desenvolve uma reflexão sobre a relação da Análise de Discurso com o Materialismo Histórico. Retomamos aqui brevemente algumas das considerações apresentadas nesse trabalho. 
domina, a hierarquia das práticas de que este modo de produção necessita, os aparelhos através dos quais se realizam estas práticas, as posições que lhe correspondem, e as representações ideológico-teóricas e ideológico-políticas que delas dependem) (Pêcheux 1971[2011], p.127)

Pêcheux (1975[1998]), em sua proposta de "uma teoria materialista dos processos discursivos", traz para o campo dos estudos da linguagem a concepção althusseriana de Ideologia, definindo-a como "uma estrutura-funcionamento que dissimula sua existência no interior mesmo do seu funcionamento, produzindo um tecido de evidências 'subjetivas', [...] 'nas quais se constitui o sujeito"' (Pêcheux 1975[1988], pp. 152-153). Citando a famosa tese central de Althusser sobre a Ideologia, a saber: A Ideologia interpela os indivíduos em sujeitos, (idem, p. 148), Pêcheux afirma que é este conceito que permite pensar "o homem" como "animal ideológico" e que lhe permite defender a tese original de que "o caráter material do sentido - mascarado por sua evidência transparente para o sujeito- consiste na sua dependência constitutiva daquilo que chamamos 'o todo complexo das formações ideológicas"” (idem, p.160), avançando desse modo em relação à reflexão althusseriana ao propor princípios teóricos e procedimentos de análise que descrevem o papel constitutivo da linguagem nos processos de interpelação ideológica, destacando, assim, a dimensão necessariamente ideológica (e, portanto, histórica) dos processos de significação.

O impacto do trabalho de Louis Althusser na reflexão de Michel Pêcheux e seu grupo de colaboradores não só é explicitado por meio de citações e referências nos textos assinados por estes autores, mas também foi objeto de importantes estudos de pesquisadores brasileiros e estrangeiros. Apenas como testemunho dessa linha de pesquisas, trazemos aqui um recorte do prefácio escrito por Denise Maldidier à publicação em francês de textos de Pêcheux, alguns até então inéditos nessa língua.

Althusser est, pour Michel Pêcheux, celui qui fait jaillir l'étincelle théorique, celui qui fait naître les projets au long cours. À tout une génération, d'ailleurs, il offrait la possibilité de "penser le marxisme hors d'une vulgate mécaniste ». Il avait notamment, en 1964, dans son article "Freud et Lacan », désigné aux marxistes inquiets de l'éternelle condamnation de la psychanalyse, cette « idéologie réactionnaire », l'horizon d'un rapprochement théorique, (Maldidier, 1990: 10)

A presença do pensamento de Althusser nos textos de Pêcheux é constante, embora seja sempre reelaborada a partir das preocupações teóricas deste autor na sua proposta de criação de uma nova região de conhecimento, cujo objeto é o discurso e cujo campo epistemológico reúne de forma crítica o Materialismo Histórico, a Linguística e a Psicanálise. Conceitos como condições de produção do sentido, efeito de sentido (constituído na posição sujeito a partir do funcionamento da figura de interpelação ideológica), formação discursiva (definida na sua articulação com a formação social e as formações ideológicas), interdiscurso (este por sua vez definido como "o todo complexo a dominante das formações discursivas), entre outros, são reelaborações originais e deslocamentos teóricos produzidos por Pêcheux em relação aos textos de Althusser, principalmente àqueles escritos entre início dos anos sessenta e fim dos anos setenta ${ }^{3}$.

Neste texto não vamos insistir sobre essa relação já suficientemente explorada; nosso objetivo é trazer para a reflexão a proposta de uma aproximação entre estes dois autores

3 Destacamos principalmente as obras Pour Marx (1965), Lire Le Capital (1965), Lenine et la philosophie (1969), Idéologie et appareils idéologiques d’État (1970), Sur la reproduction (1970), Réponse à John Lewis (1973), Élements d'autocritique (1974), Positions (1976). 
considerando os textos escritos por ambos no início dos anos oitenta e divulgados na época de diversas maneiras (como conferências, participações em eventos científicos, entrevistas concedidas, edições em outras línguas, etc.), mas que só foram publicados em francês a partir dos anos noventa. Desde 2005, ano em que traduzi para a revista Crítica marxista o célebre artigo de Louis Althusser sobre o materialismo do encontro ou materialismo aleatório ${ }^{4}$, tenho defendido a tese de uma aproximação, não só possível mas oportuna, entre os textos e avanços teóricos propostos por esses autores nos seus últimos anos de vida 5 . À diferença da relação com a obra de Althusser explicitada largamente por Pêcheux em seus próprios trabalhos, a aproximação que proponho neste artigo não conta com referências explícitas ou citações claramente identificadas na escrita destes autores; trata-se de uma interpretação plausível que defendemos a partir da leitura em paralelo da produção teórica de ambos os autores nos anos oitenta, produção contemporânea entre si, porém na qual não encontramos indicações dos autores que nos permitam afirmar que Pêcheux tinha conhecimento dos artigos ou cursos de Althusser nos quais se desenvolve a reflexão sobre a centralidade da contingência nos processos históricos, ou vice-versa, que Althusser conhecia a reflexão teórica de Pêcheux em torno da noção de acontecimento discursivo.

\section{O "último Althusser"}

No início dos anos oitenta Althusser escreve alguns textos que só serão publicados mais tarde, já na década de noventa após a sua morte, reunidos na obra Sur la philosophie (1994) ou recolhidos nas edições organizadas por François Matheron Écrits philosophiques et politiques vol. I (1994) e vol. II (1995) ou por Yves Sintomer Solitude de Machiavel $(1998)^{6}$. Destacamos ainda a publicação em espanhol das entrevistas concedidas a Fernanda Navarro Filosofía y marxismo (1988), reproduzidas na sua tradução ao francês como primeira parte do livro Sur la philosophie já citado. Estas publicações incluem ainda textos, revisados ou não por Althusser, de conferências, artigos e cursos ocorridos ainda na década de setenta, notadamente em torno do estudo de Maquiavel. Este conjunto de obras sinaliza uma inflexão na reflexão althusseriana que desde sua publicação não deixou de produzir acalorados debates no campo da filosofia, ciências políticas e sociologia, especialmente entre autores que se reconhecem na teoria marxista. Desde então têm surgido inúmeras obras dedicadas ao estudo desses textos, alimentando a polêmica sobre o pensamento do que passou a ser denominado "o último Althusser" ou "o Althusser tardio". Mencionamos aqui somente algumas dessas publicações, para conhecimento do leitor que talvez não esteja familiarizado com elas: Autour d'Althusser. Penser le matérialisme aléatoire: problèmes

4 ALTHUSSER, Louis (1982) “A corrente subterrânea do materialismo do encontro”. Trad. Mónica G. Zoppi Fontana. Em: Crítica marxista, 20, p.9-48. RJ, Ed. Revan, 2005. Disponível online em: http://www.unicamp.br/cemarx/criticamarxista/critica20-A-althusser.pdf

5 Após a tradução ao português do texto de Althusser e sua publicação na revista Crítica marxista 20 (2005), desenvolvi uma reflexão sobre a aproximação possível de ambos os autores (Pêcheux e Althusser) e de suas obras ("O discurso, estrutura e acontecimento", do primeiro, e "A corrente subterrânea do materialismo do encontro", do segundo) que apresentei em diversas ocasiões, entre elas: na conferência "Discurso e acontecimento: repetição no arquivo, contingência na historia" (jun-2005) proferida junto ao Curso de Mestrado em Linguística da Univ. Federal de Uberlândia; no curso "Teoria da Ideologia e discurso", ministrado junto à Maestría de Análisis del Discurso, Universidad de Buenos Aires (abril-2005). Como fruto dessa reflexão publiquei alguns artigos nos quais desenvolvo por extenso essa tese: Zoppi Fontana (2009), (2011), Amaral, M.V. e M.G. Zoppi Fontana (2014).

6 Esta edição traz uma correção acrescentada ao texto da conferência ministrada por Althusser na Fundação Nacional de Ciências Políticas em 11 de junho de 1977. 


\section{Conexão Letras}

et perspectives, organizado por Annie Ibrahim (2012) ; Althusser : un lecture de Marx, organizado por Jean-Claude Bourdin (2008) ; Vittorio Morfino (2006) ; os artigos de François Matheron La recurrence du vide chez Louis Althusser (2009); e de André Tosel Les alèas du matérialisme aléatoire dans la dernière philosophie de Louis Althusser (2005); os números temáticos de importantes revistas dedicados à discussão desta virada teórica no pensamento althusseriano, como da revista Multitude, 21 (2005) e da revista Décalages, vol.1 n. 1 (2013), em particular os artigos de Jean-Claude Bourdin Le reencontre du matérialisme et de l'aléatoire chez Louis Althusser (2005) e de Warren Montag El Althusser Tardio: ¿Materialismo del Encuentro o Filosofía de la Nada? (2013), respectivamente.

Pela quantidade e qualidade das publicações a que deu lugar, podemos apreciar o impacto da publicação desses textos "tardios" de Althusser, que provocaram tomadas de posição combativas e apaixonadas, seja para defender essa nova inflexão no pensamento do autor- considerada desafiadora e produtiva-, seja para decretar o fim de um pensamento que se mostraria esgotado e inútil. Como diz Tosel (2012): «Les derniers textes de Louis Althusser font problème, notamment 'Le courant souterrain du matérialisme'». Este mesmo autor resume bem o conjunto de reações provocadas no meio acadêmico pelo polêmico texto de Althusser:

Pour les uns, notamment les philosophes italiens -Vittorio Morfino, Fabrizio del Lucchese-, cet essai programatique est aussi suggestif que fascinant. Pour d'autres, il n'aurait nul autre intérêt que de témoigner du désarroi d'un marxiste contraint de renoncer à la prétention de scientificité affirmé dans sa première interprétation de Marx, celle de Pour Marx (1965) et de Lire Le Capital (1965). Sous la déconstruction de la scientificité revendiquée dans les années heureuses d'une rélaboration du matérialisme historique et de la philosophie marxienne, se cacherait alors une terrible entreprise d'autodestruction théorique. (Tosel, 2012 : 19)

Tosel reconhece na obra de Althusser três momentos diferentes que se sucedem cronologicamente e que ele denomina Althusser I, Althusser II e Althusser III. Trazemos aqui sua descrição desses três momentos porque nos interessa aproximar essa escansão temporal e teórica a outro texto, Análise de Discurso: três épocas, de autoria de Michel Pêcheux, também publicado tardiamente a partir de um manuscrito não revisado pelo autor, que teve um impacto notório e que é largamente citado por alguns autores como prova de um recuo ou refluxo das posições marxistas no desenvolvimento da teoria da Análise de Discurso. É curioso observar como ambos os textos e ambos os autores foram interpretados por aqueles que não se inscrevem em posições declaradamente materialistas como sendo a prova viva de um fracasso teórico e político. Retomando, então, a descrição de Tosel, a obra de Althusser poderia ser classificada como segue:

[Ils sont] les deux ouvrages inauguraux [Pour Marx; Lire Le Capital] qui ont fait d'Althusser le dernier philosophe marxiste d'envergure, porteur d'un programme refondateur de recherche et d'initiative politique. On pourrait nommer Althusser I ce moment. Althusser II désignerait alors le moment autocritique où, contre la déviation scientiste antérieure, il s'agirait de mieux définir la philosophie comme pratique de la lutte de classes dans la théorie et comme théorie de la lutte politique de classes au sein des appareils idéologiques d'État. Le but serait de promouvoir des effets d'une subjectivation révolutionnaire au sein de l'interpellation idéologique constituant par assujettissement le sujet juridique et moral moderne. Ce tournant autocritique commence tôt, en 1967. Chemin faisant, c'est l'idée séminale d'une rectification et d'une reconstruction de "la science marxiste du continent histoire » qui est abandonnée, tout comme est préconisée la reconnaissance de la crise irréversible du marxisme, fût-ce celui de Marx. 
La proposition du matérialisme aléatoire se veut une transformation radicale de la position philosophique et de son rapport à Marx. Elle s'anticipe dans d'autres études concernant Machiavel et elle s'exprime dans les entretiens avec Fernanda Navarro entre 1984 et 1987, publiés en 1988 sous le titre Sur la philosophie. On peut parler d'un Althusser III en rupture épistémologique et philosophique avec Althusser I et II, cessant de soutenir la scientificité inédite du Capital et renonçant au programme de travail marxiste initial. Il faut mesurer l'ampleur de ce renoncement. (Tosel, 2012:19-20)

Tosel defende na sua análise que as posições tomadas por Althusser em seus últimos textos dão continuidade e finalizam um processo de desconstrução de um princípio de Razão e de causalidade capaz de explicar o devir da história. Tosel resume esse processo de desconstrução considerando os três momentos já descritos. Segundo este autor, Althusser I recusou qualquer humanismo teórico, fazendo a crítica à categoria de alienação da essência humana e rejeitando qualquer recurso a um sujeito fundador da história. Althusser II orientou suas análises e teorizações para a questão da conjuntura e de suas contingências. Nesse sentido, propõe considerar a história como um processo sem sujeito nem fim, que se dá em conjunturas imprevisíveis, porém inteligíveis na medida em que a luta de classes está ligada às transformações do modo de produção capitalista. Finalmente, Althusser III defendeu a necessidade da contingência: tudo - estrutura, elementos, conjunturas- estaria sometido ao primado da contingência. É oportuno citar aqui uma passagem do texto de Althusser que ficou rapidamente famosa:

O todo que resulta da "pega" do encontro não é anterior à "pega" dos elementos, mas posterior, e por isso poderia não ter "pegado" e, com mais razão ainda, "o encontro poderia não ter acontecido" (Althusser, 1982/2005:32).

E ainda:

Jamais um encontro bem sucedido e que não seja breve, mas dure, garantirá sua duração ainda no dia seguinte em lugar de desaparecer. Do mesmo modo que poderia não ter acontecido, pode não acontecer mais [...] Nada garantirá jamais que a realidade do fato consumado seja a garantia de sua perenidade (Althusser, 1982/2005:14).

Tosel associa esse desenvolvimento teórico e a natureza do terceiro momento do pensamento althusseriano à conjuntura política da época:

Cette montée en puissance de la nécessité de la contingence et cet effacement du principe de raison font rupture. Ils se corrèlent avec un effacement politique des partis communistes et avec la liquidation du communisme soviétique, mais aussi avec un désespoir personnel croissant après la tragédie du meurtre d'Hélène, la femme du philosophe. (Tosel, 2012 : 27)

\section{Análise de Discurso : três épocas}

No prefácio à coletânea de textos de Michel Pêcheux reunidos para publicação, Denise Maldidier ${ }^{7}$ organiza seu relato reconhecendo no trajeto intelectual de Pêcheux três momentos, que ela nomeia como: Le temps de grandes constructions (1969-1975); Tâtonnements

7 “(Re)lire Michel Pêcheux aujourd'hui”. In : Maldidier (1990 : 7-91) [“(Re) ler Michel Pêcheux hoje” In : Maldidier (1990: 7-91)] 
(1976-1979); e La déconstruction maîtrisée (1980-1983). ${ }^{8}$ Na sua apresentação, a autora assinala o caráter reflexivo dos últimos textos de Michel Pêcheux, nos quais ele ensaia uma interpretação histórica de sua trajetória acadêmica, à que qualifica de "aventura teórica". $\mathrm{Na}$ análise desse percurso, Maldidier destaca o conceito de "estruturalismo político" proposto por Pêcheux no seu artigo Sobre a (des)construção das teorias linguísticas (1982) e retomado no seu último texto $O$ discurso. Estrutura e acontecimento (1983). Conforme a autora, Pêcheux trouxe este conceito para propor uma demarcação no interior do estruturalismo que designaria um espaço de encontro intelectual com autores como Foucault, Lacan e Derrida, além de Althusser, em torno da questão da linguagem. Trata-se da contestação radical de uma concepção de linguagem que a defina como instrumento de comunicação, o que acarreta a crítica à noção de sujeito psicológico 9 . Nas palavras do autor: "O efeito subversivo da trilogia Marx-Freud-Saussure foi um desafio intelectual engajando a promessa de uma revolução cultural que coloca em causa as evidências da ordem humana como estritamente bio-social" (Pêcheux, 1983: 45).

Nesse espaço teórico Pêcheux ocupou um lugar totalmente original, ao pensar o sujeito ideológico (reflexão iniciada por Althusser) na materialidade específica da língua (contribuição inédita de Pêcheux). Os últimos textos de Pêcheux, aqueles que correspondem à autodenominada "terceira época da Análise de Discurso" investiriam em um movimento de "desconstrução controlada" ("déconstruction maîtrisée", nas palavras de Maldidier, 1990) de uma tendência a uma sobreinterpretação estruturalista, que funcionaria como um dispositivo de tradução de "enunciados empíricos vulgares" por "enunciados estruturais conceptuais"; tratar-se-ia, segundo Pêcheux (1983a: 46), de evitar o "narcisismo da estrutura" inscrito no espaço teórico que ele identificou como "estruturalismo político"10.

No seu texto Análise de Discurso: três épocas, Pêcheux explicita os elementos alvo de desconstrução e as tentativas de mudança tanto teórica quanto metodológica. Este texto, datado em 1983, se caracteriza por reunir um conjunto de anotações de Michel Pêcheux não revisadas nem publicadas em vida por este autor. Permaneceu inédito em francês até a edição crítica da obra de Pêcheux organizada por Denise Maldidier ${ }^{11}$ e publicada em 1990. Sua tradução ao português foi publicada também em 1990 na coletânea de textos organizada por Gadet e Hak ${ }^{12}$, cuja tradução ficou a cargo de uma equipe de pesquisadores liderados por Eni Orlandi. Nesse texto o autor propõe a substituição das "máquinas discursivas" que ele identifica com a primeira época da Análise de Discurso por "máquinas paradoxais", nas quais se imponha o primado do outro como espaço interdiscursivo que intervém nas formulações e como memória discursiva na qual se inscrevem os enunciados. Assim, o

8 André Tosel (2012), no seu artigo sobre o materialismo do encontro que já mencionamos, também reconhece três momentos no percurso intelectual de Althusser, aos quais nomeia por meio dos subtítulos de seu texto como: Althusser I: science du continent histoire et programme de recherche; Althusser II: rectification "politique", autocritique et crise; e Althusser III: une déconstruction radicale pour quel commencement? O paralelo entre as trajetórias de Althusser e Pêcheux, conforme a interpretação daqueles que estudaram sua obra não deixa de ser notável.

9 Vale a pena lembrar o paralelo que Maldidier estabelece entre esta noção de "estruturalismo político" presente nos textos de Pêcheux e a expressão "anti-humanismo teórico" de Althusser. A autora afirma em nota de rodapé a seu prefácio Re(lire) Michel Pêcheux aujourd'hui que: "On peut penser que le struturalisme politique reformule, dans le contexte des années 1980, la position qu'avait représentée l'expression althussérienne d' " antihumanisme théorique " (Maldidier, 1990 : 87).

10 Contudo, como bem lembra Maldidier (1990:88): "Segundo Paul Henry, nem Michel Pêcheux, nem Althusser, nem Foucault, nem Lacan, nem Derrida podem ser considerados como "estruturalistas", dada sua ruptura radical com uma noção de natureza humana como princípio explicativo.

11 Maldidier, D. (org.) L'inquiétude du discours. Textes de Michel Pêcheux. Paris: Ed. des Ceindres, 1990.

12 Gadet, F. e T. Hak (org.) Por uma Análise Automática do Discurso. Campinas: Ed. da Unicamp, 1990. 
discurso-outro, compreendido como heterogeneidade constitutiva, deveria intervir tanto na construção do corpus (não mais ancorado em condições de produção estáveis ou em espaços ideológicos homogêneos) quanto na sua análise (que comporta diversos momentos, organizados "em espiral", de descrição e interpretação alternadas e recorrentes).

A reflexão em torno do acontecimento discursivo e a reformulação teórica do objeto da Análise de Discurso que daí se depreende se insere nesse último momento da trajetória de Michel Pêcheux e aparece largamente desenvolvida no seu último texto $O$ discurso. Estrutura e acontecimento (1983). A publicação em português da conferência originalmente ministrada e publicada em inglês data de 1990 e é contemporânea à publicação da versão em francês deste texto, incluído na coletânea organizada por Maldidier. Embora seja nessa obra que a noção de acontecimento é definida e mobilizada na prática de análise de enunciados concretos, ela já tinha aparecido em textos anteriores, notadamente Leitura e memória: projeto de pesquisa (1982), sempre relacionada à noção de memória discursiva. A oposição/batimento entre acontecimento e estrutura interfere no modo de organização e exploração do corpus, mas principalmente afeta o modo de compreensão teórica do objeto discurso. É esta dimensão teórica e epistemológica da noção de acontecimento que nos interessa neste artigo, embora reconheçamos o impacto que ela teve nos procedimentos de análise, dando lugar a preciosas reflexões em torno da identificação de um acontecimento discursivo no corpus e de sua diferenciação em relação a outros tipos de acontecimento (histórico, enunciativo, jornalístico). ${ }^{13}$

Esta dupla visada teórica e metodológica aparece já explicitada no próprio texto de Pêcheux, dividido textualmente em três partes que poderíamos grosso modo caracterizar como sendo a primeira voltada à explicitação de procedimentos de análise das formulações em relação ao acontecimento discursivo e a memória; a segunda, de natureza mais epistemológica, revisa a relação ciência / marxismo / estruturalismo; e finalmente a terceira parte desenvolve uma reflexão teórica sobre o discurso como acontecimento, colocando no centro a noção de equívoco.

Neste nosso artigo focamos a reflexão justamente sobre essa compreensão do acontecimento como dimensão constitutiva do objeto discurso.

\section{Discurso e acontecimento}

Em trabalhos anteriores (Zoppi Fontana, 1997; 2002; 2005) já mobilizamos a noção de acontecimento discursivo na exploração e análise do corpus, o que nos levou a trabalhá-la também teoricamente, considerando sua relação com a noção de memória discursiva. A partir da definição de Pêcheux do acontecimento discursivo como o "ponto de encontro de uma atualidade e uma memória" ${ }^{14}$, insistíamos no impacto sobre os processos discursivos de um elemento histórico descontínuo e exterior que afeta a memória produzindo ruptura e deslocamentos, o que nos levou a compreender

o acontecimento discursivo como o lugar material onde o real da língua e o real da história se encontram produzindo uma ruptura, uma interrupção e uma emergência nas relações de continuidade definidas pelos rituais enunciativos que conformam as práticas discursivas na sua historicidade. (Zoppi Fontana, 1997).

13 Remetemos aqui à leitura das análises reveladoras de Dela Silva (2009), Indursky (2003), Mittmann (1999), entre outros.

14 Pêcheux (1983a:17). 


\section{Conexão Letras}

Assim, na caracterização do discurso como acontecimento proposta por Pêcheux destacamos, como já o fizemos anteriormente (Zoppi Fontana, 2009), a afirmação explícita de uma possibilidade de transformação em aberto, realizada ou realizável, no simples fato de um discurso ter existência: o seu potencial efeito desestruturador-desregularizador; sua relação constitutiva com o irrealizado.

Não se trata de pretender aqui que todo discurso seria como um aerólito miraculoso, independente das redes de memória e dos trajetos sociais nos quais ele irrompe, mas sublinhar que, só por sua existência, todo discurso marca a possibilidade de uma desestruturação-reestruturação dessas redes e trajetos. (Pêcheux, 1983a: 56)

Esta afirmação do autor, que coloca na própria existência do discurso a possibilidade de interromper uma série de repetições, dando lugar a uma "desestruturação-reestruturação" da memória e das práticas discursivas, leva a pensar o discurso como acontecimento, ou seja, a considerar o acontecimento como uma dimensão constitutiva do objeto discurso. Observe-se que no trecho citado, assim como em outros nos quais Pêcheux aproxima a noção de acontecimento à de equívoco, o autor faz uma afirmação sobre o funcionamento de todo discurso, portanto, define e caracteriza o discurso enquanto objeto teórico, explicitando as propriedades ou dimensões que o constituem.

Todo discurso é o índice potencial de uma agitação nas filiações sócio-históricas de identificação, na medida em que ele constitui ao mesmo tempo um efeito dessas filiações e um trabalho (mais ou menos consciente, deliberado, construído ou não, mas de todo modo atravessado pelas determinações inconscientes) de deslocamento no seu espaço. (Pêcheux, 1983a: 56)

Poucas linhas mais adiante na mesma obra, Pêcheux (1983a : 57) esclarece que "a análise de discurso não supõe de forma alguma a possibilidade de algum cálculo dos deslocamentos de filiação e das condições de felicidade ou de infelicidade evenemenciais". Estas passagens do texto são largamente citadas por autores que focam sua reflexão no funcionamento da interpelação ideológica (e do assujeitamento) na constituição do sujeito do discurso, refletindo sobre as falhas que a atravessam como efeito necessário do equívoco que habita na língua.

Nosso foco dirige a atenção para outro aspecto do texto que já apontamos em trabalhos anteriores (Zoppi Fontana, 2009; 2011): a compreensão do conceito mesmo de acontecimento e sua aproximação com os trabalhos de Althusser sobre o materialismo do encontro. Trata-se de retomar a discussão sobre a (sobre)determinação histórica dos processos de significação e especificamente sobre a relação constitutiva do real da língua e do real da história no discurso, definido como objeto paradoxal.

Como aponta Maldidier (1990: 92)

tratava-se agora de construir 'máquinas paradoxais' [que permitissem abordar] 'este espaço aberto de retomadas, formando trajetos em redes de textos (com pontos de acumulação instáveis, organizando redes de memória provisoriamente regularizadas, expostos ao choque dos acontecimentos).

Retomando a discussão já feita no início deste artigo sobre a obra do "último Althusser", defendemos a tese de que a noção de acontecimento pode ser aproximada da noção de encontro ou pega proposta por Althusser e, sendo assim, deve ser compreendida a partir 
do primado da contingência. Dito de outra maneira, proponho considerar o acontecimento do discurso - ou seja, o discurso na sua dimensão de acontecimento- na sua contingência constitutiva. Se todo discurso é compreendido por Pêcheux como um "índice potencial de agitação nas filiações sócio-históricas e nas redes e trajetos de memória", entendo que todo discurso é constitutivamente habitado pelo acontecimento, compreendido na sua radical contingência histórica. Retomando as considerações de Althusser nos seus últimos trabalhos, podemos interpretar a noção de acontecimento do discurso e no discurso como a irrupção de um vir-a-ser-consumado (o encontro entre uma atualidade e uma memória) que poderia não ter sido ou que poderia vir-a-ser-outro ou vir-a-não-ser ${ }^{15}$. Nesse sentido, o discurso, na sua dimensão de acontecimento, isto é, considerando sua inscrição no real da história, mantém uma relação constitutiva com o irrealizado, que pelo primado da contingência que rege os processos históricos, conforme posto por Althusser, não pode ser confundido com um impossível nem com nenhum regime de causalidade estrutural ou de finalidade teleológica.

Nos seus textos tardios Althusser, sem negar a sobredeterminação dos processos históricos, abre o conceito de história para a indeterminação potencial desses mesmos processos ${ }^{16}$. Ou seja, como diz o próprio autor: "Em lugar de pensar a contingência como modalidade ou exceção da necessidade, é necessário pensar a necessidade como o vir-a-ser-necessário do encontro de contingentes" (Althusser, 1982/2005:p.29)

Refletindo sobre o materialismo aleatório, Moulier-Boutang (2005) analisa o conceito de aléas ou acaso/contingência presente na obra de Althusser e suas consequências para pensar os processos históricos e a prática política.

Si l'événement historique est "matériel" par excellence, c'est parce qu'il résiste à toute prédictibilité d'émergence. Sa singularité absolue ne peut faire l'objet d'un calcul rationnel d'anticipation, ni de rétropolation ex post dans une téléologie des « lois de la nature ». Une histoire en tant qu'elle obéit à un développement du bouton vers la fleur, n'est pas matérialiste. [...] Seul un matérialiste aléatoire pourra ne pas essuyer le démenti systématique des « faits» et approcher l'art de la politique révolutionnaire. La révolution est un événement irréductible, imprévisible, «surdéterminé ». La causalité univoque, la continuité ne sont d'aucune utilité. Le matérialisme aléatoire, c'est la politique, mais pas n'importe quelle espèce de politique : une politique de la révolution, de la fondation de quelque chose de radicalement nouveau. Inanité des preuves de la nécessité de l'existence de la révolution. (Moulier-Boutang, 2005)

Note-se que o acontecimento histórico, o encontro, não somente é imprevisível, mas, também, não é necessário: a necessidade é efeito de sua ocorrência e de sua duração, não sua causa.

Esta mesma concepção de história parece-me estar na base da compreensão do discurso como acontecimento significante, que Orlandi define de forma original, retomando a relação estrutura/acontecimento trabalhada por Pêcheux ${ }^{17}$.

15 Em Zoppi Fontana (2009) explicito e fundamento esta aproximação da noção de acontecimento à noção de encontro, que define para Althusser a história, pensada na sua contingência radical, conforme a tradição filosófica do materialismo aleatório.

16 É importante enfatizar que a singularidade e imprevisibilidade do acontecimento é resultado do excesso / acúmulo de múltiplas determinações e não de uma insuficiência ou falta de determinação dos processos históricos e do sujeito. Esta ressalva é imprescindível para que a tese do primado da contingência não seja lida (como de fato já o foi) como a afirmação do "reino da liberdade" (o sujeito estaria finalmente livre da ideologia - e do inconsciente! - para agir conforme sua vontade e consciência).

17 Cf. Zoppi Fontana (2011), onde abordo a questão do estatuto teórico da noção de equívoco na Análise de Discurso na sua relação com o real da história e o funcionamento do silêncio no discurso. 
Trabalhamos continuamente a articulação entre estrutura e acontecimento: nem o exatamente fixado, nem a liberdade em ato. Sujeitos, ao mesmo tempo, à língua e à história, ao estabilizado e ao irrealizado, os homens e os sentidos fazem seus percursos, mantém a linha, se detêm junto às margens, ultrapassam limites, transbordam, refluem. No discurso, no movimento do simbólico, que não se fecha e que tem na língua e na história sua materialidade. (Orlandi, 1999: 53)

É o acontecimento do objeto simbólico que nos afeta como sujeitos. Algo do mundo tem de ressoar no "teatro da consciência" do sujeito para que faça sentido. [...] Não se trata apenas de um jogo de significantes descarnados, embora a língua como sistema significante importe e muito. Para ressoar, é preciso a forma material, a língua-e-a-história. [...] Se de um lado, a linguagem tem sua parte na injunção a significar, de outro, o mundo exerce sua força inexorável. (Orlandi, 2001: 102).

\section{Acontecimento e equívoco}

Como já posto neste artigo e em trabalhos anteriores ${ }^{18}$, na minha reflexão aproximo a noção de encontro em Althusser à noção de acontecimento em Pêcheux, para pensar a questão do real da história na conceituação do discurso.

Pêcheux insiste, num parágrafo largamente citado nos trabalhos da área, sobre os "pontos de deriva possíveis" que assombram todo enunciado do seu interior. Essa possibilidade do sentido vir a ser outro constitui para o autor o "equívoco da língua".

Todo enunciado é intrinsecamente suscetível de tornar-se outro, diferente de si mesmo, se deslocar discursivamente de seu sentido para um outro (a não ser que a proibição da interpretação própria ao logicamente estável se exerça sobre ele explicitamente) (Pêcheux, 1983a: 53)

Esta citação, comumente interpretada em relação ao real da língua, permite-nos lançar sobre o enunciado (portanto sobre o discurso) um olhar que considere também o real da história, entendido (como já vimos) como contingência radical. Desta maneira, o enunciado (o fato consumado, o encontro que "pegou") é assombrado, mesmo depois de produzido (isto é, do acontecimento de sua enunciação) pela instabilidade radical de sua ocorrência, isto é, pela possibilidade nunca cancelada de o sentido vir-a-ser-outro ou de vir-a-não-ser (ou seja, de não durar o suficiente para produzir um encontro "feliz", um sentido que "pegue" historicamente dando lugar à estabilização de um processo discursivo).

A partir dessa aproximação, tentamos mostrar que em relação ao objeto teórico discurso podemos pensar o real da história no seu funcionamento específico sem reduzí-lo ao real da língua. Como já defendi em outro trabalho (Zoppi Fontana, 2009), se o real da língua se funda em um impossível, o real da história se funda no possível, isto é, não há necessidade nem impossibilidade que estruture a priori os processos históricos. A articulação destas duas ordens materiais irredutíveis no seu funcionamento, sobredetermina conjuntamente os processos de produção de sentido e do sujeito, tomados no fundo duplo de identificações falhas e de indeterminação histórica. Neste sentido, entendo o discurso como um objeto paradoxal.

Considerar o discurso como um objeto paradoxal, tal como o fazemos seguindo a reflexão de Pêcheux (1983c[2010]), nos permite manter teoricamente a diferença entre os conceitos de acontecimento e equívoco.

18 Zoppi Fontana (2009; 2011; 2014). 
Com efeito, acontecimento e equívoco, como dimensões constitutivas do objeto discurso não se confundem. $\mathrm{O}$ irrealizado histórico não se confunde com o impossível da ordem simbólica, mas também não se submete a sua lei.

Retomando e deslocando ao mesmo tempo o parágrafo que citamos do último texto de Pêcheux (1983a), Orlandi sublinha decididamente a intervenção da história na produção do equívoco.

É aqui que faz sentido a distinção entre falha e equívoco que tenho procurado desenvolver. A língua é capaz de falha. Essa possibilidade - a da falha - é constitutiva da ordem simbólica. Por seu lado, o equívoco já é fato de discurso, ou seja, é a inscrição da língua (capaz de falha) na história que produz o equívoco.[...] O equívoco é falha da língua, na história. (Orlandi, 2001: 102-103)

Assim podemos afirmar que, se o equívoco é efeito da falha da língua na historia, $o$ acontecimento discursivo é efeito da contingência da história na língua. Encontro paradoxal de duas ordens irredutíveis no objeto teórico de uma disciplina desafiadora.

Encontro paradoxal, também, de dois autores que subverteram as projeções narcísicas do pensamento de sua época, tanto na sua vertente positivista quanto no "estruturalismo político" que pretendia revolucionar a ciência e a política da segunda metade do século XX.

Pierre Macherey (2005) aponta para as consequências filosóficas e políticas do percurso teórico de Althusser, marcado pela sua tomada de posição explícita por um anti-humanismo teórico. Macherey cita no seu artigo uma passagem do livro Lire Le Capital:

Dans la réduction de toute connaissance aux rapports sociaux historiques, on peut introduire em sous-main une seconde réduction, qui traite les rapports de production comme de simples rapports humains - cette subreption est courante dans touts les interprétations humanistes du marxisme. Cette seconde réduction repose sur une « évidence » : [...] que les « acteurs» de l'histoire sont les auteurs de son texte, les sujets de sa production. [...] Il suffit d'escamoter le metteur en scène pour que l'acteur-auteur ressemble comme un frère au vieux rêve d'Aristote : le médecin-qui-se-soigne-lui-même : et que les rapports de production qui sont pourtant proprement les metteurs en scène de l'histoire, se réduisent à de simples rapports humains. (Althusser Lire Le Capital, p. 338-339 apud Macherey, 2005 : 154)

Por causa de Althusser e de seus textos decididamente contrários à corrente do humanismo filosófico e do marxismo reformista as práticas sócio-históricas e seus sujeitos não podem ser confundidas com a evidência empírica da ação de atores sociais e, consequentemente, as relações de produção não podem ser reduzidas a ou naturalizadas como simples relações humanas (entre atores sociais que interagem na sociedade).

Da mesma forma, podemos salientar o impacto da obra de Michel Pêcheux no campo das ciências da linguagem e especialmente da Análise de Discurso; ele rompe com as evidências de um sujeito bio-psico-social em interação comunicativa e produz uma ruptura epistemológica na abordagem das práticas discursivas na sua relação constitutiva com a história. Como bem o mostra Maldidier (1990), por causa de Pêcheux o discurso não pode ser reduzido a sua evidência empírica e, acrescentamos, o estudo da produção histórica do sentido não pode ficar restrito à descrição da diversidade cultural das interações humanas ou à complexidade dos seus contextos pragmáticos.

Le parcours de Michel Pêcheux a déplacé quelque chose. D'un bout à l'autre, ce qu'il a théorisé sous le nom de « discours » est le rappel de quelques idées aussi simples qu'insup- 
portables : le sujet n'est pas la source du sens; le sens se forme dans l'histoire à travers le travail de la mémoire, l'incessante reprise du déjà-dit ; le sens peut être traqué, il échappe toujours. À cause de Michel Pêcheux, le discours, dans le champ français, ne se confond pas avec son évidence empirique ; il représente une forme de résistance intellectuelle à la tentation pragmatique. Maldidier, $1990: 89)$

Para Bourdin, o último Althusser e sua proposta do materialismo aleatório não constituiria uma nova filosofia ou um novo materialismo, mas seria uma forma nova de fazer filosofia sendo materialista.

Adopter ce matérialisme n'est donc pas défendre une philosophie contre une autre (ou deux autres), mais c'est se livrer à une pratique. Le matérialisme de la rencontre ou matérialisme aléatoire [MR/MA] est alors l'instrument d'une pratique de la philosophie et d'une pratique du matérialisme. Pour reprendre une distinction éclairante de Pierre Macherey, on dira que le MR/MA n'est pas une philosophie matérialiste, mais une façon nouvelle de faire de la philosophie en matérialiste. (Bourdin, $2012: 59$ ).

De nossa parte, nós aprendemos com Pêcheux a praticar a análise de discurso sendo e permanecendo materialistas.

\section{Referências}

AMARAL, M. Virgínia e Mónica ZOPPI FONTANA. Análise de discurso e o materialismo histórico. In: FERREIRA, M. Cristina L; Freda INDURSKY; Solange MITTMANN. Michel Pêcheux: 30 anos de uma presença. Porto Alegre: UFRGS, no prelo BOURDIN, Jean-Claude La rencontre du matérialisme et de l'aléatoire chez Louis Althusser. In : Multitudes. 21. Mineure 21. Le matérialisme aléatoire et le «dernier Althusser ». 2005. Disponível em: http://www.multitudes.net/category/l-edition-papier-en-ligne/multitudes-21-ete-2005/mineure-le-materialisme-aleatoire/

. Org. Althusser : une lecture de Marx. Paris: PUF, 2008

.Ce que fait la reencontre aléatoire au matérialisme (et à la philosophie). In : IBRAHIM, Annie Autour d'Althusser. Paris: Le Temps des Cerises, 2012, p. 54-82 DELA SILVA, Silmara $O$ acontecimento discursivo da televisão no Brasil: a imprensa na constituição da TV como grande mídia. Tese de doutorado. Campinas: Instituto de Estudos da Linguagem/UNICAMP, 2008. Disponível em: http://www.bibliotecadigital. unicamp.br/document/?code $=000436084 \&$ opt $=4$

HAROCHE, Claudine.; HENRY, Paul.; PÊCHEUX, Michel (1971[2007]) “A Semântica e o corte saussuriano: língua, linguagem, discurso", in: BARONAS, R. L. Análise do discurso: apontamentos para uma história da noção-conceito de formação discursiva. São Carlos: Pedro \& João Editores, pp. 13-32.

IBRAHIM, Annie. Org. Autour d'Althusser. Paris: Le Temps des Cerises, 2012. INDURSKY, Freda Lula lá : estrutura e acontecimento. In: Organon, vol 17. $n$ 35, 2003, p. 101-121 Disponível em: http://seer.ufrgs.br/index.php/organon/article/ view/30020/18616

MACHEREY, Pierre Verum et factum : les enjeux d'une philosophie de la praxis et le debat Althusser-Gramsci. In : KOUVÉLAKIS, E. e V. CHARBONNIER Sartre, Luckács, Althusser, des marxiste en philosophie. Paris: Presse Universitaire de France, 2005, p. 143-156 
MALDIDIER, Denise. «(Re)lire Michel Pêcheux aujourd'hui». In : L'inquietude du discours. Paris: Éditions des Cendres, 1990. Trad. de Eni Orlandi. A inquietação do discurso. Campinas: Pontes, 2003.

MATHERON, François La récurrence du vide chez Louis Althusser. In : ALTHUSSER, Louis Maquiavel et nous. Paris: ed. Tallandier, 2009, p. 205-235

MITTMANN, Solange Nem lá, nem aquí: o percurso de um enunciado. In: FERREIRA, M. Cristina L. e Freda Indursky Os múltiplos territórios da Análise de Discurso. Porto Alegre: Sagra-Luzzatto, 1999.

MONTAG, Warren El Althusser Tardío: ¿Materialismo del Encuentro o Filosofía de la Nada? Trad. Aurelio S. Pezonaga. In : Décalages. Vol 1. $n$ 1. Disponível em t: http:// scholar.oxy.edu/decalages/vol1/iss $1 / 2$

MORFINO, Vittorio O primado do encontro sobre a forma. In: Crítica Marxista, 23, p. 11-33. Disponível em: http://www.ifch.unicamp.br/criticamarxista/arquivos_biblioteca/ artigo126artigo1.pdf

MOULIER-BOUTANG, Yann Le matérialisme comme politique aléatoire. In : Multitudes. 21. Mineure 21. Le matérialisme aléatoire et le "dernier Althusser ». 2005. Disponível em: http://www.multitudes.net/category/l-edition-papier-en-ligne/multitudes-21-ete-2005/mineure-le-materialisme-aleatoire/

ORLANDI, Eni Discurso e texto. Formulação e circulação de sentidos. Campinas: Pontes, 2001.

PÊCHEUX, Michel. Les Vérités de la Palice. Linguistique, Semantique, Philosophie.

$1^{a}$ ed. Paris, Maspero, 1975. Trad. Eni P. de Orlandi et alii. Semântica e Discurso. Uma

Crítica à Afirmação do Óbvio. Campinas: Editora da UNICAMP, 1988.

"Lecture et mémoire: project de recherche". (1982). In: L'inquietude du discours. Paris, Ed. des Cendres, 1990. Em Análise de Discurso. Michel Pêcheux. Textos escolhidos por Eni Orlandi. Campinas: Pontes, 2011

. Le discours: structure ou événement? (1983a) In : D. MALDIDIER L'Inquietude $\overline{d u}$ discours. Paris, Ed. des Cendres, 1990. Trad: Eni P. de Orlandi. O discurso: Estrutura ou Acontecimento Campinas: Pontes, 1990.

Analyse de discours : trois époques. (1983b) In : L'inquietude du discours. Paris, Ed. des Cendres, 1990. Em: Gadet, F. e T. Hak Por uma análise automática do discurso. Campinas: Editora da Unicamp, 1990.

. Ideologie - Festung oder paradoxer Raum? Das Argument, núm 139, p. 379-387.

Berlin: $1983 \mathrm{c}$

TOSEL, André Les aléas du matérialisme aléatoire dans la dernière philosophie de Louis Althusser. In : KOUVÉLAKIS, E. e V. CHARBONNIER Sartre, Luckács, Althusser, des marxiste en philosophie. Paris: Presse Universitaire de France, 2005, p.169-196

. Matérialisme de la reencontre et pensée de l'évenement-miracle. In : IBRAHIM, Annie. Org. Autour d'Althusser. Paris: Le Temps des Cerises, 2012, 19-53

ZOPPI FONTANA, Mónica O acontecimento do discurso na contingência da história. In:FERREIRA, M.C. \& F. INDURSKY (org.) O discurso na contemporaneidade: materialidades e fronteiras. São Carlos: Claraluz, 2009. p. 133-146 Disponível em: http://issuu. com/prazeremler/docs/contemporaneidade

. Estar em estado de palavra. In: RODRIGUES, E.; SANTOS, G.; BRANCO, L. Análise de Discurso no Brasil. Pensando o impensado sempre. Uma homenagem a Eni Orlandi. Campinas: RG Editora, 2011, p.69-86 